\title{
Development of Cervical and Uterine Malignancies During Follow-Up After Manchester-Fothergill Procedure
}

\author{
Katrine Engelbredt, MD, ${ }^{1}$ Karin Glavind, MD, ${ }^{2}$ and Niels Kjaergaard, MD, $\mathrm{PhD}^{2}$
}

\begin{abstract}
Objective: This study was conducted to assess the risk of cervical or uterine malignancy development following pelvic organ prolapse (POP) surgery using the Manchester-Fothergill procedure, with the aim of elucidating the potential risks of uterine-conserving surgical treatment of POP.

Materials and Methods: This study included Manchester-Fothergill procedures performed at Aalborg University Hospital, in Aalborg, Denmark, from 1996 to 2016. Information was retrieved regarding patient parity, body mass index, and smoking status, as well as data from postsurgical Papanicolaou smears, endometrial biopsies, and cervical and endometrial histopathologic analyses. Data were collected from the electronic medical records and the Danish Urogynecological database

Results: A total of 299 Manchester-Fothergill procedures were included, with a mean follow-up time of 7.8 years (range: 0-21.4 years). After surgery, histopathologic analyses revealed abnormal cervical or uterine developments in 6 patients: simple benign endometrial hyperplasia without atypia in 5 patients, and cervical intraepithelial neoplasia, which turned normal 6 months later in 1 patient.

Conclusions: There appears to be a low risk of developing cervical or uterine malignancy after the ManchesterFothergill procedure. Additional studies are needed to examine the risks and benefits of uterus-sparing procedures further. ( $\mathrm{J}$ GYNECOL SURG 36:60)
\end{abstract}

Keywords: pelvic organ prolapse, POP, cervical pathology, uterine pathology, Manchester-Fothergill procedure, risk of malignancy.

\section{Introduction}

$\mathbf{P}$ ELVIC ORGAN PROLAPSE (POP) is a common condition among females, with an $11 \%$ lifetime risk of undergoing at least 1 operation for POP or urinary incontinence. ${ }^{1}$ POP may have a negative impact on a patient's quality of life, daily activities, and social relationships. Treatments for POP include both conservative (nonsurgical) and surgical approaches. ${ }^{2}$ Vaginal hysterectomy is the most-common surgical procedure for apical prolapse treatment and is usually combined with other reconstructive procedures for the pelvic floor. $^{3,4}$

During the last decade, there has been growing interest in uterus-sparing procedures among gynecologists, and such procedures have been requested by patients increasingly. ${ }^{5} \mathrm{~A}$ recent survey study reported that $60 \%$ of women would decline hysterectomy if offered an equivalent uterinesparing prolapse procedure. The factors that influence pa- tients' decisions regarding surgical treatment include their doctors' opinions, the risks of surgical complications, and the risks of malignancy if the uterus is preserved. ${ }^{6}$

Several uterus-sparing surgical techniques are available, including the Manchester-Fothergill procedure. Compared to vaginal hysterectomy, cervical resection seems to be equally effective for uterine prolapse treatment, and is associated with lower rates of morbidity and severe complications. Prior investigations comparing hysterectomy with cervical resection have shown a significantly longer mean duration of surgery and greater mean amount of blood loss in hysterectomy groups compared with cervical resection groups. Vaginal hysterectomy groups also required longer hospitalizations and longer recovery times. ${ }^{4,7}$ Moreover, the Manchester-Fothergill procedure is substantially less expensive than vaginal hysterectomy. Selection of the ManchesterFothergill procedure over vaginal hysterectomy for apical prolapse treatment reduces healthcare costs by one-third. ${ }^{8}$

\footnotetext{
${ }^{1}$ Department of Clinical Medicine, Aalborg University, Aalborg, Denmark.

${ }^{2}$ Department of Obstetrics and Gynecology, Aalborg University Hospital, Aalborg, Denmark.
} 
However, despite the renewed interest in uterine preservation and the apparent advantages of uterine-sparing procedures, very little information is available regarding the long-term outcomes of uterine-sparing prolapse surgery.

The present study was conducted to investigate the risk of cervical or uterine malignancy development further after POP surgery by the Manchester-Fothergill procedure. This information is intended to elucidate the potential risks of uterine conservation that might be connected with the surgical treatment of POP.

\section{Materials and Methods}

This study included women who had undergone a Manchester-Fothergill procedure at Aalborg University Hospital, in Aalborg, Denmark, between March 1996 and December 2016. These patients' electronic medical records (EMRs) were identified for review, using common procedural terminology codes for women with symptomatic POP. Prior to the Manchester-Fothergill procedure, all patients had been evaluated by ultrasound (US). Postmenopausal women who showed endometrial thickness of $>4 \mathrm{~mm}$ on US had undergone endometrial biopsy. All women in the study group (as all Danish women) were advised to follow the guidelines from The National Board of Health. The followup time for each patient was defined as the time between the Manchester-Fothergill procedure up to performance of a hysterectomy, death, or November 2017 (Fig. 1).

Data were collected from the patients' EMRs, the Danish Urogynecological database (DugaBase), and the Danish National Pathology Registry. Data from the different databases were merged using the patients' personal identification numbers in the Danish Civil Registration system. The DugaBase includes data regarding all surgeries for POP and urinary incontinence performed in public or private hospitals in Denmark. Reporting to the DugaBase is compulsory by law, resulting in very high coverage of the database (> 90\%). The DugaBase registry includes information regarding each patient's age, body mass index (BMI), and parity. The Danish National Pathology Registry includes data regarding all analyzed tissue samples from public and private hospitals, as well as from the primary sector, in Denmark. Information was retrieved regarding Papanicolaou (Pap) smear testing after Manchester-Fothergill

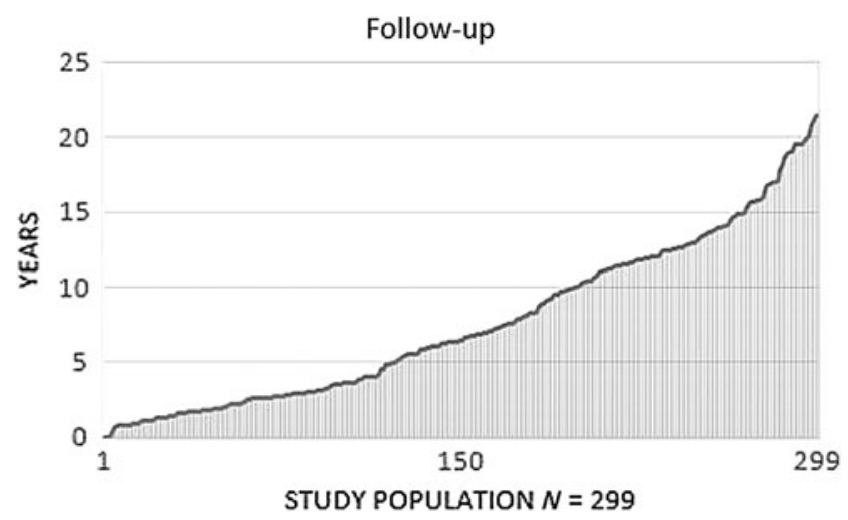

FIG. 1. Follow-up time (mean: 7.8 years) for the study population of 299 women. procedures, uterus tissues after Manchester-Fothergill procedures, and pathologic reports from hysterectomies. ${ }^{8}$ information was also retrieved regarding each patient's age, BMI, smoking, parity, and menopausal status.

Patients had been referred from Region Nordjylland, which has a population of 582,632 . Due to its geographical position and infrastructure, women from this region rarely receive treatment in other regions. The Danish National Pathology Registry includes information about patients from every region of Denmark. The Danish Health Service is financed by progressive income taxes, and every citizen has access to state health insurance. This insurance covers free medical consultations from doctors and specialists, and it is likely that few postmenopausal women with uterine bleeding do not seek medical care.

\section{Cervical screening}

In Denmark, when women reach age 23 , they are automatically summoned to a voluntary cervical screening program, in which a general practitioner obtains cell samples at predetermined intervals. Women between ages 23 and 49 are summoned for screening every 3 years, and women between ages 50 and 64 are summoned every 5 years for screening. The screening program continues even when cervical resection has been performed.

\section{Clinical guidelines for suspected endometrial cancer}

When a postmenopausal woman experiences uterine bleeding, it is recommended that she visit her general practitioner the same day or the following day. If the general practitioner cannot find a reason for the abnormal bleeding, the patient is referred to a gynecologist at a hospital or to a private gynecology clinic. Investigation includes a gynecologic examination, a pelvic examination, and a transvaginal US examination. If the endometrium is thicker than $4 \mathrm{~mm}$, an endometrial biopsy is performed. ${ }^{10}$

\section{Manchester-Fothergill procedure}

The Manchester-Fothergill procedure was recognized and has been used to treat uterovaginal prolapse since 1936 in the United States. ${ }^{11}$

Small-toothed forceps are applied, one immediately below the external urethral meatus, one on each side of the cervix, and one posteriorly. An incision is then made to join these points, with the depth being just sufficient to allow the vaginal skin to roll away and peel back easily from the bladder.

Using the knife or scissors, and starting at the apex of the incision, the skin is peeled back to expose the bladder and the cervix. The cardinal ligaments are then clamped, divided, and transfixed. The cervix is amputated with the knife (and there should be no bleeding, given that the blood vessels have already been tied). The cervix is re-covered with a Sturmdorf suture. The whole circumference of the amputated cervix is then re-covered. The Fothergill stitch is the top one, which picks up the vaginal skin, and the cut ends of the cardinal ligaments are passed through the cervix. See Figure 2.

The Manchester-Fothergill procedure can be accompanied by anterior and/or posterior colporrhaphy. The 


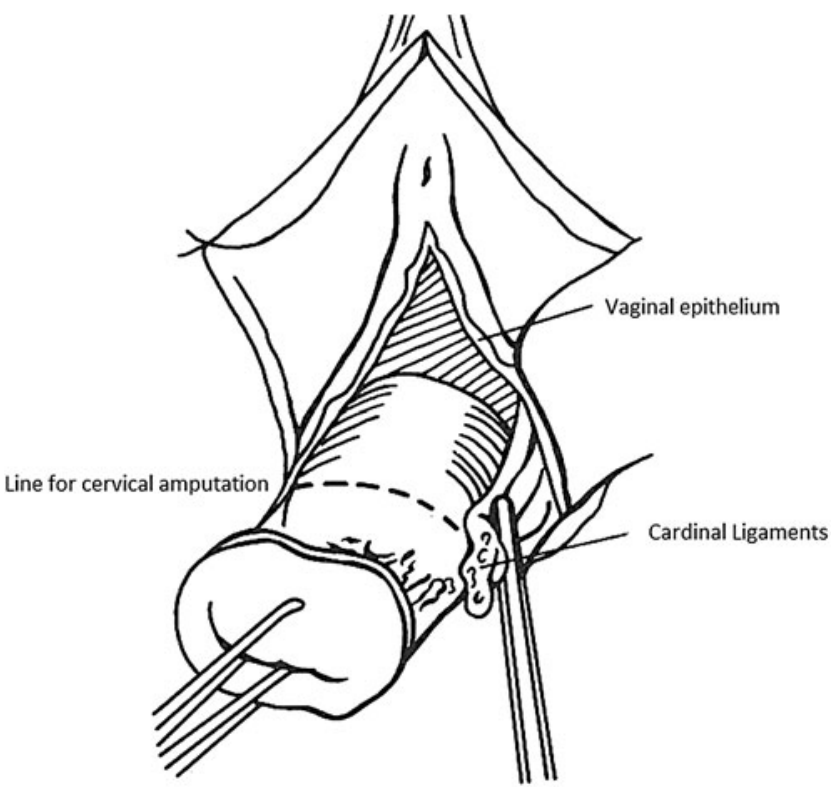

FIG. 2. Manchester-Fothergill procedure. The cardinal ligaments are clamped, divided, and transfixed. Drawings by Ane Markussen and Lisbeth Jensen. ${ }^{13}$ Illustration reproduced with permission.

peritoneum of the abdominal cavity is not opened during the Manchester-Fothergill procedure (Fig 2). ${ }^{12,13}$

\section{Statistics}

Medians, 95\% confidence intervals (CIs), and ranges were calculated, using SPSS statistics. Age, parity, and BMI were tested for normality using the Shapiro-Wilk test. The data were not normally distributed, and only a small number of women had pathology after the Manchester-Fothergill procedure; therefore, a Mann-Whitney- $U$ test was used to calculate $p$-values.

\section{Ethical approval}

This study was approved by the Danish Data Protection Agency (date of issue: September 20, 2017; registration number: 2017-189). Individual patient consents were not required, because this study was classified as a register research study under Danish law.

\section{Results}

Figure 1 shows the follow-up time (median: 7.8 years; 95\% CI: 6.9-8.2; range: 0-21.4 years). A total of 27 patients $(9 \%)$ died during the study period, and they were included in the follow-up until their dates of death. Ten deaths were cancer-related: 1 from breast cancer; 1 from pancreatic cancer; 1 from a glioblastoma; 1 from signet-cell carcinoma; 1 from rectal/colon cancer; 1 from an intestinal adenocarcinoma; 1 from a relapse of ovarian cancer; 1 from lung cancer, 1 from an adenocarcinoma (probably from the pancreas); and 1 from larynx cancer. Eleven women died of medical causes that were not cancer-related. Six women died of unknown causes; these deaths occurred at the ages of $64,73,82,82,83$, and 83 .
Ten women $(3.3 \%)$ underwent hysterectomy after the Manchester-Fothergill procedure. Reasons included reprolapse, patient preference, postmenopausal bleeding, abnormal uterine appearance, and unexpected cervical carcinoma at the time of Manchester-Fothergill procedure. Notably, these 10 women all had normal uterine histology at the time of hysterectomy.

A total of 159 women $(58 \%)$ underwent 1 or more Pap smear tests after the Manchester-Fothergill procedure, with a mean of 2 Pap tests per woman (range: 1-11; 328 total tests performed). One case of cervical intraepithelial neoplasia 1 (CIN 1) was identified, which had turned normal after 6 months. Endometrial biopsies were performed in 21 women $(7 \%)$, which identified 5 cases of endometrial hyperplasia without atypia.

Of the 6 women with abnormal histopathologic findings after the Manchester-Fothergill procedure, 5 (83\%) were premenopausal at the time of the procedure. The mean time from the procedure until the detection of abnormal histopathologic findings was 3.9 years. This group of 6 women (2\%) was significantly younger (mean age: 48.2 years) at the time of Manchester-Fothergill surgery, compared to the remainder of the study population (median age: 57.8 years) $(p=0.046)$. The 2 groups did not statistically differ in BMI or parity. It was difficult to reach a conclusion regarding smoking due to the low number of women with histopathologic findings (Table 1).

\section{Discussion}

In the current study population of 299 women who underwent Manchester-Fothergill procedures, no cervical or uterine malignancies were detected during the mean followup time of 7.8 years. This result could have been influenced by the relatively small size of the study population. Region Nordjylland has a population of 582,632, and the estimated annual incidences of cervix cancer and endometrial cancer are 35 and 75 , respectively. ${ }^{14}$

The current authors would assume that, in most cases, the squamocolumnar junction is probably surgically removed during the Manchester-Fothergill procedure, such that the cervical cancer rate would likely be lower than in the rest of the female Danish population. In contrast, the uterine body is not altered by the Manchester-Fothergill procedure; therefore, the rate of endometrial cancer/hyperplasia in the uterine body is probably no different from in the rest of the female Danish population. Thus, it is still important that a woman visit her general practitioner if she experiences postmenopausal vaginal bleeding after a Manchester-Fothergill procedure.

A total of 328 Pap smear tests were performed after Manchester-Fothergill procedures in the study population. In 1 patient $(0.3 \%)$, cervical biopsy after the ManchesterFothergill procedure revealed CIN 1. This biopsy was performed 8 years after the Manchester-Fothergill procedure. A Pap smear test performed 6 months later revealed that the CIN 1 had turned back to normal cells.

Twenty-one patients in the current study group underwent endometrial biopsies after their Manchester-Fothergill procedures. Five of these patients $(1.7 \%)$ were found to have developed simple endometrial hyperplasia, a benign condition. This frequency is in accordance with previous 
Table 1. Clinical Characteristics When Undergoing the Manchester-Fothergill Procedure Among Women with Normal and Abnormal Postsurgical Uterine Histopathologic Findings

\begin{tabular}{|c|c|c|}
\hline Characteristics & $\begin{array}{l}\text { Normal histopathology after } \\
\text { Manchester-Fothergill procedure }(\mathrm{n}=293 ; 98 \%)\end{array}$ & $\begin{array}{c}\text { Abnormal histopathology after } \\
\text { Manchester-Fothergill procedure }(\mathrm{n}=5 ; 1.7 \%)\end{array}$ \\
\hline \multirow[t]{3}{*}{ BMI $\left(\mathrm{kg} / \mathrm{m}^{2}\right)$} & Mean: 27.2 & Median: 28.2 \\
\hline & $95 \%$ CI: 26.6-28.1 & $95 \%$ CI: $16.3-39.9$ \\
\hline & Range: 17.3-58.7 & Range: 23.3-32.8 \\
\hline \multicolumn{3}{|l|}{ Smoking } \\
\hline Never smoker & $104(35 \%)$ & 2 \\
\hline Ex-smoker & $58(19 \%)$ & 1 \\
\hline Current smoker & 24 (8\%; mean: $13.7 /$ day $)$ & - \\
\hline Unknown & $113(38 \%)$ & 2 \\
\hline \multirow[t]{3}{*}{ Age (yrs) } & Mean: 57.8 & Median: 50 \\
\hline & $95 \%$ CI: $56.3-59.3$ & $95 \%$ CI: $44-53.3$ \\
\hline & Range: $25-82$ & Range: $45-53$ \\
\hline \multirow[t]{3}{*}{ Parity } & Mean: 2.3 & Median: 2 \\
\hline & $95 \%$ CI: $2.1-2.4$ & $95 \%$ CI: $1.6-2.7$ \\
\hline & Range: 0-6 & Range: 2 \\
\hline Premenopausal & $97(32 \%)$ & $4(80 \%)$ \\
\hline Postmenopausal & $173(58 \%)$ & - \\
\hline Unknown & $29(10 \%)$ & $1(20 \%)$ \\
\hline
\end{tabular}

Values are given as mean, $95 \% \mathrm{CI}$, range, number $(n)$, or $\%$.

$\mathrm{CI}$, confidence interval; yrs, years.

reports. ${ }^{15,16}$ These 5 patients with abnormal uterine histopathologic findings after the Manchester-Fothergill procedure were significantly younger (median age: 49 years) at the time of the operation, compared to the rest of the population (mean age: 57.8 years). At the time of endometrial hyperplasia diagnosis, these 5 patients were postmenopausal. It is a matter of interest whether a Manchester-Fothergill procedure may delay or complicate the diagnosis of malignancy by occluding the cervical canal. In the current study, nothing in the medical reports indicated the presence of cervical stenosis or difficulties in obtaining endometrial biopsies.

Only a few studies have examined the future risks of abnormal histopathologic findings after uterine-sparing surgery for POP, and the results of these studies differ with respect to the postoperational risk of developing cervical or uterine pathology. In an English study from 1970, Tipton and Atkin ${ }^{17}$ examined 82 premenopausal patients for 6-12 years after they underwent the Manchester-Fothergill procedure; the researchers found that 2 patients $(2.4 \%)$ developed endometrial carcinoma during this follow-up time.

The present study results were in accordance with the findings of 2 recent studies. A 2006 Turkish retrospective study examined 204 primarily premenopausal women over a median follow-up time of 5 years after Manchester-Fothergill procedure and reported that none of the patients developed uterine carcinoma. ${ }^{18}$ Another study from the United States, in 2016, compared 4 different surgical routes for uterine-sparing procedures to treat prolapse. Of the 240 women included in that study, none had abnormal uterine histopathologic findings during the follow-up period, which ranged from 6 to 22.6 months, with a median of only $\sim 1$ year. ${ }^{19}$

\section{Strengths and limitations}

Strengths of the current study included the large age range of patients at the time of their Manchester-Fothergill procedures. Additionally, the mean follow-up time was 7.8 years, which was an advantage given that cervical and uterine pathologies develop over long periods of time. One limitation of the current study was the relatively small study population. A larger sample would provide a better representation of the population.

\section{Conclusions}

There appears to be only a low risk of developing cervical or uterine malignancy after a Manchester-Fothergill procedure. Additional studies are needed to investigate the risks and benefits of uterus-sparing procedures further.

\section{Author Disclosure Statement}

No financial conflicts of interest exist.

\section{Funding Information}

No funding was received for this article.

\section{References}

1. Olsen AL, Smith VJ, Bergstrom JO, Colling JC, Clark AL. Epidemiology of surgically managed pelvic organ prolapse and urinary incontinence. Obstet Gynecol 1997;89:501.

2. Grigoriadis T, Athanasiou S, Giannoulis G, Mylona SC, Lourantou D, Antsaklis A. Translation and psychometric evaluation of the Greek short forms of two conditionspecific quality of life questionnaires for women with pelvic floor disorders: PFDI-20 and PFIQ-7. Int Urogynecol J 2013;24:2131.

3. Jha S, Moran P. The UK national prolapse survey: 5 years on. Int Urogynecol J 2011;22:517.

4. Bergman I, Soderberg MW, Kjaeldgaard A, Ek M. Cervical amputation versus vaginal hysterectomy: A populationbased register study. Int Urogynecol J 2017;28:257.

5. Wu MP, Long CY, Huang KH, Chu CC, Liang CC, Tang $\mathrm{CH}$. Changing trends of surgical approaches for uterine 
prolapse: An 11-year population-based nationwide descriptive study. Int Urogynecol J 2012;23:865.

6. Frick AC, Barber MD, Paraiso MF, Ridgeway B, Jelovsek JE, Walters MD. Attitudes toward hysterectomy in women undergoing evaluation for uterovaginal prolapse. Female Pelvic Med Reconstr Surg 2013;19:103.

7. Unlubilgin E, Sivaslioglu AA, Ilhan TT, Kumtepe Y, Dolen I. Which one is the appropriate approach for uterine prolapse: Manchester procedure or vaginal hysterectomy? Turkiye Klin J Med Sci 2013;33:321.

8. Husby KR, Tolstrup CK, Lose G, Klarskov N. ManchesterFothergill procedure versus vaginal hysterectomy with uterosacral ligament suspension: An activity-based costing analysis. Int Urogynecol J 2018;29:1161.

9. Sundhedsstyrelsen. Screening Programme for Cervix Cancer [in Danish], vol. 2017. 2017. Online document at: www .sst.dk/da/sygdom-og-behandling/screening/livmoderhalskr aeftscreening Accessed February 20, 2019.

10. Danish National Health Service, Programme for Suspected Endometrial Cancer [in Danish], vol. 2018. 2018. Online document at: www.sst.dk/da/udgivelser/2016/ /media/46E 00C3CBC1E4AD39690ADFBBB889704.ashx Accessed February 20, 2019.

11. Conger GT, Keettel WC. The Manchester-Fothergill operation, its place in gynecology; a review of 960 cases at University Hospitals, Iowa City, Iowa. Am J Obstet Gynecol 1958;76:634.

12. Rob C, Smith R. Fothergill pelvic floor repair (Manchester Operation). In: Dudley H, ed. Operative SurgeryFundamental International Techniques, 3rd ed. London: The Butterworth Group, 1979. 63-69.

13. Jørgen Kjer J, Ottesen B, Lundvall F. Vaginal operations. In: Operative Gynecology, 1st ed. [in Danish]. København: Munksgaard, 1989. 150-151.
14. Sundhedsdatastyrrelsen. Danish Cancer Registry-Annual Report 2015, Vol. 2017 [in Danish]. 2016. Online document at: https://sundhedsdatastyrelsen.dk/da/nyheder/2016/ cancerregistret-2015_16122016 Accessed February 20, 2019.

15. Jokubkiene L, Sladkevicius P, Valentin L. Transvaginal ultrasound examination of the endometrium in postmenopausal women without vaginal bleeding. Ultrasound Obstet Gynecol 2016;48:390.

16. Breijer MC, Peeters JA, Opmeer BC, Clark TJ, Verheijen RH, Mol BW, Timmermans A. Capacity of endometrial thickness measurement to diagnose endometrial carcinoma in asymptomatic postmenopausal women: A systematic review and meta-analysis. Ultrasound Obstet Gynecol 2012;40:621.

17. Tipton RH, Atkin PF. Uterine disease after the Manchester repair operation. J Obstet Gynaecol Br Commonw 1970;77: 852.

18. Ayhan A, Esin S, Guven S, Salman C, Ozyuncu O. The Manchester operation for uterine prolapse. Int J Gynaecol Obstet 2006;92:228.

19. Kow N, Goldman HB, Ridgeway B. Uterine conservation during prolapse repair: 9-year experience at a single institution. Female Pelvic Med Reconstr Surg 2016;22:126.

Address correspondence to: Niels Kjaergaard, MD, PhD

Department of Obstetrics and Gynecology Aalborg University Hospital

Reberbansgade 15

Aalborg, DK 9000

Denmark

E-mail: nikj@rn.dk 